\title{
Sedentary Behavior And Physical Activity are Independently Associated With Obesity in Young Brazilians: A Quantile Regression Analysis
}

\author{
Camilo Luis Monteiro Lourenço, ${ }^{1}$ Edmar Lacerda Mendes ${ }^{2}$
}

\begin{abstract}
Objective: to test whether sedentary behavior (SB) and moderate to vigorous physical activity MVPA were independently associated with the distribution of different BMI percentiles in a representative sample of Brazilian youth. Methods: This is a cross-sectional school-based study $(n=1,023)$, including young (14-21y; $54 \%$ female) from public and private schools in a Brazilian city. The survey was conducted in 2015 and the young self-reported both SB (screen time) and MVPA behaviors. Height and body mass were measured to calculate BMI. Quantile regression was used to investigate the association between SB, MVPA, and BMI distribution percentiles (P10 ..., P90; statistical significance $p<.01$ ). Results: SB and MVPA were associated with higher and lower BMI values, respectively. Quantile regression revealed that the associations were nonlinear and stronger in the upper BMI percentiles. Also, in the adjusted models (SB and MVPA in the same model), the associations were enhanced for MVPA. For example, each additional hour of MVPA at P10 was associated with $-0.05(p<.01)$ lower BMI value, against -0.09 at P50 $(p<.01)$ and even lower at P90, $-0.24(p<.01)$. Conclusion: SB and MVPA were independently and nonlinearly associated with BMI in our sample of Brazilian youth. The associations were more notable in the higher percentiles of the BMI distribution. Our findings suggest that nonlinearity between exposures and outcomes should be considered when proposing future strategies for obesity prevention in youth.
\end{abstract}

Keywords: Sedentary lifestyle; motor activity; nutritional status; cross-sectional studies.

\section{COMPORTAMENTO SEDENTÁRIO E ATIVIDADE FÍSICA SÃO INDEPENDENTEMENTE ASSOCIADOS} À OBESIDADE EM JOVENS BRASILEIROS: UMA ANÁLISE DE REGRESSÃO QUANTÍLICA

\section{RESUMO}

Objetivo: testar se comportamento sedentário (CS) e Atividade Física de Moderada a Vigorosa Intensidade (AFMV) são independentemente associados à distribuição de diferentes percentis do Índice de Massa Corporal (IMC) em uma amostra representativa local de jovens brasileiros. Métodos: este é um estudo transversal de base populacional escolar ( $n=1.023 ; 14-21 y$; 54\% feminino), incluindo jovens de escolas públicas e privadas de uma cidade do Brasil. O levantamento foi conduzido em 2015 e os jovens autorrelataram CS (tempo diante da tela) e AFMV. Estatura e massa corporal foram mensuradas para calcular o IMC. A regressão quantílica foi usada para investigar a associação entre CS, AFMV e os percentis da distribuição do IMC (P10..., P90; significância estatística $\mathrm{p}<.01)$. Resultados: CS e AFMV foram associados com maiores e menores valores do IMC, respectivamente. A regressão quantílica revelou que as associações foram não lineares e mais fortes nos percentis superiores do IMC. Ainda, nos modelos ajustados (CS e AFMV no mesmo modelo), as associações foram potencializadas para AFMV. Por exemplo, cada hora adicional de AFMV no P10 foi associado com $-0.05(p<.01)$ menor valor do IMC; contra -0.09 no P50 ( $p<.01)$ e menor ainda no P90, -0.24 $(p<.01)$. Conclusões: CS e AFMV foram independentemente e não linearmente associados ao IMC em nossa amostra de jovens brasileiros. As associações foram mais expressivas nos percentis superiores da distribuição do IMC. Nossos achados sugerem que é preciso considerar a não linearidade entre as exposições e o desfecho quando da proposição de estratégias futuras para prevenção da obesidade em jovens.

Palavras-chave: Estilo de vida sedentário; atividade motora; estado nutricional; estudos transversais.

RECEBIDO EM: 10/3/2020

MODIFICAÇÕES SOLICITADAS EM: 1\%/4/2021

ACEITO EM: 21/6/2021

\footnotetext{
${ }^{1}$ Autor correspondente. Universidade Federal do Vale do São Francisco - Av. Jose de Sa Manicoba s/n, Centro. 56304-917. Petrolina/PE, Brasil. http://lattes.cnpq.br/2736235722039751. https://orcid.org/0000-0003-0231-1702. camilo.lourenco@univasf.edu.com

2 Universidade Federal do Triângulo Mineiro - Departamento de Ciências do Esporte. Uberaba/MG, Brasil.
} 


\section{INTRODUCTION}

It is estimated that one in four Latin American adolescents is overweight, ${ }^{1}$ over $50 \%$ of Brazilian adolescents have excessive sedentary behavior $(\mathrm{SB})^{2}$ and $84 \%$ do not of them meet recommendations of moderate to vigorous physical activity (MVPA). ${ }^{3}$ Increased time in SB concomitantly with reduced MVPA may be the ideal scenario for the increase in pediatric obesity levels. ${ }^{4}$ Additionally, there is epidemiological evidence that the association between SB and obesity does not depend on MVPA, although this is not conclusive ${ }^{5}$ and the results are limited to testing by conventional statistical models.

The statistical methods used to investigate the association between SB, MVPA, and pediatric obesity are mostly applied with logistic models (categorized outcome) or reduced to means (ordinary linear regression). These models may fail to reveal important information. For example, ordinary linear regression fails to present the results of the association between SB and higher percentiles (90th percentile) of the body mass index (BMI) distribution. On the other hand, quantile regression, which is a regression method aimed at estimating either the conditional median or other quantiles of a continuous variable ${ }^{6}$, has the advantage of exploring how predictors (e.g. SB and MVPA) impact the shape of the distribution of a continuous variable (e.g. BMI).

Although quantile regression has been used to explore the association of SB and MVPA with BMI in a study with young people, ${ }^{7}$ its use is still incipient in clinical and epidemiological studies. ${ }^{6}$ This type of regression analysis presents less intuitive interpretation than conventional regression methods, which is the reason given by Beyerlein and colleagues ${ }^{6}$ for its infrequent use. Moreover, as far as we know, no study investigating SB among Brazilian young people has used this type of statistical modeling so far. ${ }^{2}$ Thus, the present study aimed to test whether SB and MVPA were independently associated with the distribution of different BMI percentiles in a representative sample of Brazilian youth.

\section{MATERIAL AND METHODS}

\section{Study design and data source}

The present study is reported according to the Strengthening the Reporting of Observational Studies in Epidemiology (Strobe) statement ${ }^{8}$ (Appendix A).

The Study of Assessment of Adolescent Health and Lifestyle Behaviors in Uberaba (ACtVU Study) was a school population-based survey that included a representative sample of high school youth from public and private schools in Uberaba, Minas Gerais, Brazil. The ACtVU Study was conducted between May and October 2015 in Uberaba- a municipality with a population of 295,988 inhabitants located 481 kilometers from Belo Horizonte, capital of the state of Minas Gerais.

The sample size of ACtVU Study was estimated considering: the survey population ( $N=10,903$ - number of high school enrollments in 2015), the prevalence of SB (50\%), sampling error (5\%), two-point design effect (deff $=2$ ) and addi- 
tion of $20 \%$ and $10 \%$ for loss/refusal and confounding analysis, respectively. The estimated final sample was of 979 participants, calculated using Epi Info ${ }^{\mathrm{TM}} 7$. The sample selection process was clustered, proportional, stratified and random, in two stages: the selection of 15 schools (public $=9$, private $=6$, out of 36 eligible schools- Stage 1) and 50 classes (out of 362 eligible classes- Stage 2). All students present in the classroom at the time of collection were eligible to participate. In the present study, we included young people aged 14 to 21 years with complete data for MVPA, SB, anthropometry, and covariates from the database of the ACtVU Study. The age range adopted in the present study maximizes the representativeness of the survey population and is closer to the definition of "young people", according to the World Health Organization. ${ }^{9}$

\section{Ethical considerations}

All parties involved in the ACtVU Study consented/assented to participate. The local research ethics committee approved the study protocol (case number 994,772/2015) The Department of Minas Gerais State and the Regional Superintendency of Education of Uberaba authorized the study. The youth and their guardians consented/assented to participate. The ACtVU Study was conducted in compliance with the Declaration of Helsinki.

\section{Estimates of SB and MVPA}

Time in SB and MVPA was obtained through a previously validated questionnaire ${ }^{10}$. Sedentary behavior was estimated based on the time that the young people spent in front of screens (time watching the television and the computer and/or video game). They answered about the time (hours and minutes) spent on weekdays (Monday to Friday) and weekends (Saturday and Sunday) in these behaviors. The amount of time per day (weighted average [five days of the week and two days of the weekend]) was divided by the number of days to estimate the h/day of SB.

Moderate to vigorous physical activity was estimated based on the self-reported frequency (number of days) and the amount of time per day (hours and minutes) of MVPA. Young people were instructed to consider MVPA performed in a typical week in the fields of leisure, work, and travel. The amount of time per day was divided by the number of days to estimate MVPA h/day.

\section{BMI Measure}

Body mass index was calculated as body mass $(\mathrm{kg})$ divided by squared height $\left(\mathrm{m}^{2}\right)$. Body mass was measured using a digital scale (Wiso ${ }^{\circledR}$, w939, capacity $180 \mathrm{~kg}$ ) and height was measured using a portable stadiometer (WCS ${ }^{\oplus}$, Wood Portable Compact, capacity $220 \mathrm{~cm}$, graduation $1 \mathrm{~mm}$ ). These measurements were made using standardized methods by trained personnel (physical education students and teachers). Body mass index is the outcome of our study (continuous variable) and is expressed in $\mathrm{kg} / \mathrm{m}^{2}$. 


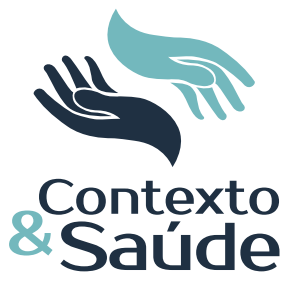

\section{Covariables}

As age increases, SB tends to increase, ${ }^{11}$ MVPA tends to decrease ${ }^{12}$ and obesity tends to increase, ${ }^{13}$ thus, we include age as covariate (self-reported in full years until the date of the survey). Moreover, due to the difference between boys and girls for SB and physical activity, ${ }^{11}$ sex was also included as a covariate (self-reported as female and male). In Brazil, school dependence (public and private) and the shift (day and night) are intrinsically related to the variables of interest of the present study; ${ }^{14}$ thus, we entered the type of school and school shift as covariates (school type and shift were recorded by the research team). Sleep outcomes, such as duration and delay time, are affected by screen-based $\mathrm{SB} ;{ }^{15}$ thus, we included sleep time as a covariate (self-reported in hours of sleep per day). Our results showed differences in the proportions between sexes and mean age of participants, reinforcing the inclusion of these covariates (Table 1).

\section{Statistical analysis}

Continuous variables were represented by measures of central tendency and dispersion (mean and standard deviation, median, and quartiles) and categorical variables by relative and absolute frequencies. Independent t-test, Mann-Whitney $\mathrm{U}$ test, and chi-square test were used to compare differences between sexes. Body mass index categories were defined according to sex and age-specific cutoff points according to the International Obesity Task Force ${ }^{16}$ up to 18 years, and adult cutoff points for the others. ${ }^{17}$ To meet the objective of this study, we used quantile regression, entering BMI as a dependent variable in the models. This regression method uses the median (rather than the mean) of the outcome variable and any other percentile of interest throughout its distribution without necessarily categorizing participants according to cutoff points. In the present study, four regression models were created. First, we tested whether SB (h/day) was associated with BMI $\left(\mathrm{kg} / \mathrm{m}^{2}\right)$, adjusting for covariates (model 1a). Then we tested whether MVPA (h/day) was associated with BMI $\left(\mathrm{kg} / \mathrm{m}^{2}\right)$, adjusting for covariates (model 1b). We then inserted SB and MVPA in the same model (model 2) to test whether SB and MVPA were independently associated with the outcome (BMI). The percentiles (P) 10 (P10), P25, P50, P75, and P90 of BMI were tested to represent the lower fractions, the middle fractions, and the upper fractions of the frequency distribution of this variable. In quantile regressions, we adopted the Bofinger bandwidth, excluding omitted cases, tolerance of singularity of $10^{-12}$, a convergence of $10^{-6}$, and estimated standard errors using 2000 iterations. For comparative purposes, we run and present the linear regression coefficients with the same covariates. All analyses were conducted in SPSS 26. Data collected from ACtVU were double-entered into Epidata Entry forms, with automatic typing validation. Inconsistencies between the two-typing data were verified by a third researcher, accessing the questionnaires for manual corrections. To incorporate the sampling procedure into the analyses, we calculated and used sample weights in all analyses of this study. Because of this, we increased the accuracy of the hypothesis tests and considered the results to be statistically significant if p-value $<.01$ ( $99 \%$ confidence intervals).

Editora Unijuí - Revista Contexto \& Saúde - ISSN 2176-7114 - v. 21, n. 44, out./dez. 2021 


\section{RESULTS}

\section{Description of participants}

A total of 1,363 young people was approached in the classroom and invited to participate in the ACtVU Study. However, 295 of them did not consent/ assent to participate. Thus, the final sample of young people in this study, aged between 14 and 21 years, was of 1,023 participants, of whom 54\% were females (Table 1).

Males and females showed similar mean values for age and BMI. The median time spent on SB was 5.9 hours per day while the median time spent on MVPA was 68.9 minutes per day. Seven out of ten young people in our sample had a normal BMI. Information on characteristics stratified by sex is shown in Table 1.

Table 1 - Sample characteristics. ACtVU Study 2015, Brazil

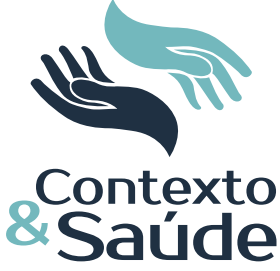

\begin{tabular}{lcccc}
\hline Variables & All & Females & Males & p-value \\
\hline Age, mean (SD), years & $16.1(1.3)$ & $16.0(1.2)$ & $16.2(1.4)$ & \\
BMI, mean (SD), kg/m² & $22.1(4.0)$ & $22.0(4.1)$ & $22.3(4.1)$ & \\
SB, MD (Q25-75), h/day & $5.9(3.5 ; 9.1)$ & $5.4(2.9 ; 8.4)$ & $6.2(3.9 ; 9.6)$ & $<.001$ \\
MVPA, MD (Q25-75), min/day & $68.6(34.3 ; 102.9)$ & $51.4(34.3 ; 85.7)$ & $68.6(51.4 ; 120.0)$ & $<.001$ \\
BMI categories, \% (N) & & & & \\
$\quad$ Normal & $75.2(716)$ & $73.9(387)$ & $75.1(329)$ & \\
$\quad$ Overweight & $19.8(188)$ & $21.4(106)$ & $19.1(82)$ & \\
$\quad$ Obesity & $5.0(48)$ & $4.7(21)$ & $5.8(27)$ &
\end{tabular}

Abbreviations: SD, standard deviation; MD, median; Q25-75, first and third quantiles, respectively; SB; sedentary behavior; MVPA, moderate to vigorous physical activity; BMI, body mass index.

c, 71 missing data.

Fonte: Dados da pesquisa.

\section{Quantile regressions of SB and $\mathrm{BMI}$}

More time spent on SB was associated with higher BMI and these associations were even stronger in the higher percentiles of BMI distribution (Table 2). For example, at P50, each additional hour of SB was associated with 0.07 (p $<.001$ ) higher BMI values. In contrast, in the two upper percentiles, P75 and P90, each additional hour of SB was associated with $0.14(p<.001)$ and $0.25(p<.001)$ higher BMI values, respectively (Table 2 , model 1 a). After adjusting for MVPA, the strength of the association was increased (for P50 and P75), and SB remained associated with $\mathrm{BMI}$ in the upper three percentiles, i.e., at P50 $(\beta=0.08, p<.001)$, P75 ( $\beta=0.20, p<.001)$ and P90 $(\beta=0.23, p<.001)$. In turn, there was no statistical significance for the lower two percentiles (P10, $\beta=-0.01, p=.059 ; P 25, \beta$ $=-0.01, p=.027)$. No major changes were identified in the sensitivity analysis, which included 14-18-year-old (Table 3).

The visual representation of the association between SB and the distribution of BMI percentiles is shown in Figure 1. A visual inspection of the Figure and the $99 \% \mathrm{Cl}$ values allows us to infer that the association of SB with BMI in P90 was stronger than that in P10 in both models ( $1 \mathrm{a}$ and 2, the difference between $\beta=|0.22|)$. Furthermore, for comparison purposes, the linear regression coeffi- 
cients also appear plotted in Figure 1 (model $1 \mathrm{a}, \beta=0.08,99 \% \mathrm{Cl}: 0.071 ; 0.100, \mathrm{p}$ $<.001$; model $2, \beta=0.10,99 \% \mathrm{Cl}: 0.09 ; 0.12, \mathrm{p}<.001)$.

\section{Quantile regressions of MVPA and BMI}

Greater time of MVPA was associated with lower BMI and such association was even stronger in the higher percentiles of BMI distribution (Table 2). For example, at P50 each additional hour of MVPA was associated with $0.08(p<.001)$ lower BMI values. In contrast, in the upper two percentiles, P75 and P90, each additional hour of MVPA were associated with $0.12(p<.001)$ and $0.13(p<.001)$ lower BMI values, respectively (Table 2 , model $1 \mathrm{~b}$ ). After adjustment for SB, each additional hour of MVPA was associated with lower BMI values in the lower percentiles (P10, $\beta=-0.05, p<.001 ; P 25, \beta=-0.07, p<.001)$ and MVPA showed an even stronger association with lower BMI values (P50, $\beta=-0.09, p<.001 ; P 75$, $\beta=-0.16, p<.001 ; P 90,=-0.24, p<.001$ ) (Table 2, model 2 ). No major changes were identified in the sensitivity analysis, which included 14-18-year-old (Table 3) - except P10, which showed an inverse association (Table 3, model 1b).

The visual representation of the association between MVPA and BMI percentiles is shown in Figure 1. A visual inspection of Figure 1 and the $99 \% \mathrm{Cl}$ allows us to infer that the association of MVPA with BMI in P90 was stronger than that seen in P10, in both models (model $1 b$, the difference between $\beta=|0.08|$; model 2 , the difference between $\beta=|0.19|$ ). Additionally, for comparison purposes, the linear regression coefficients also appear plotted in Figure 1 (model $1 b, \beta=-0.06$, 99\% Cl: $-0.08 ;-0.04, p<.001$; model $2, \beta=-0.14,99 \% \mathrm{Cl}:-0.18$; $-0.11, p<.001)$. 


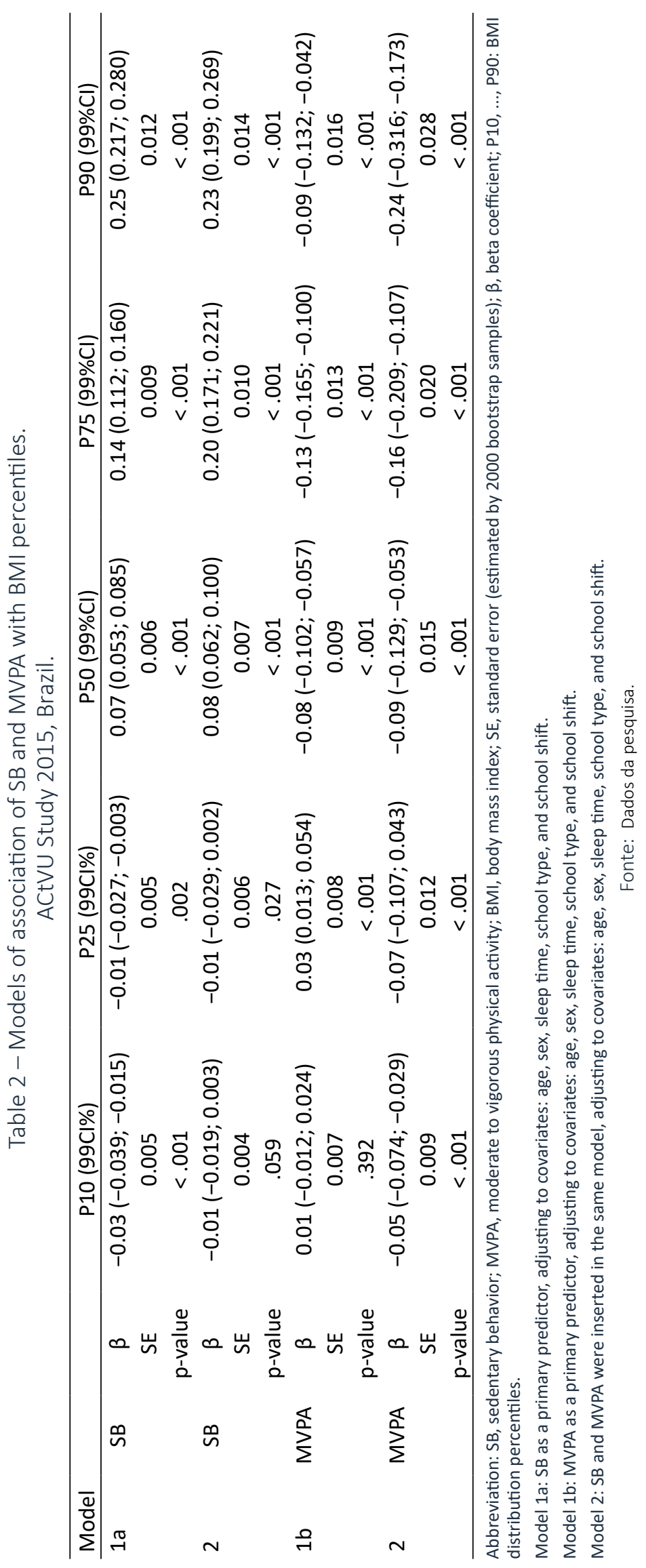




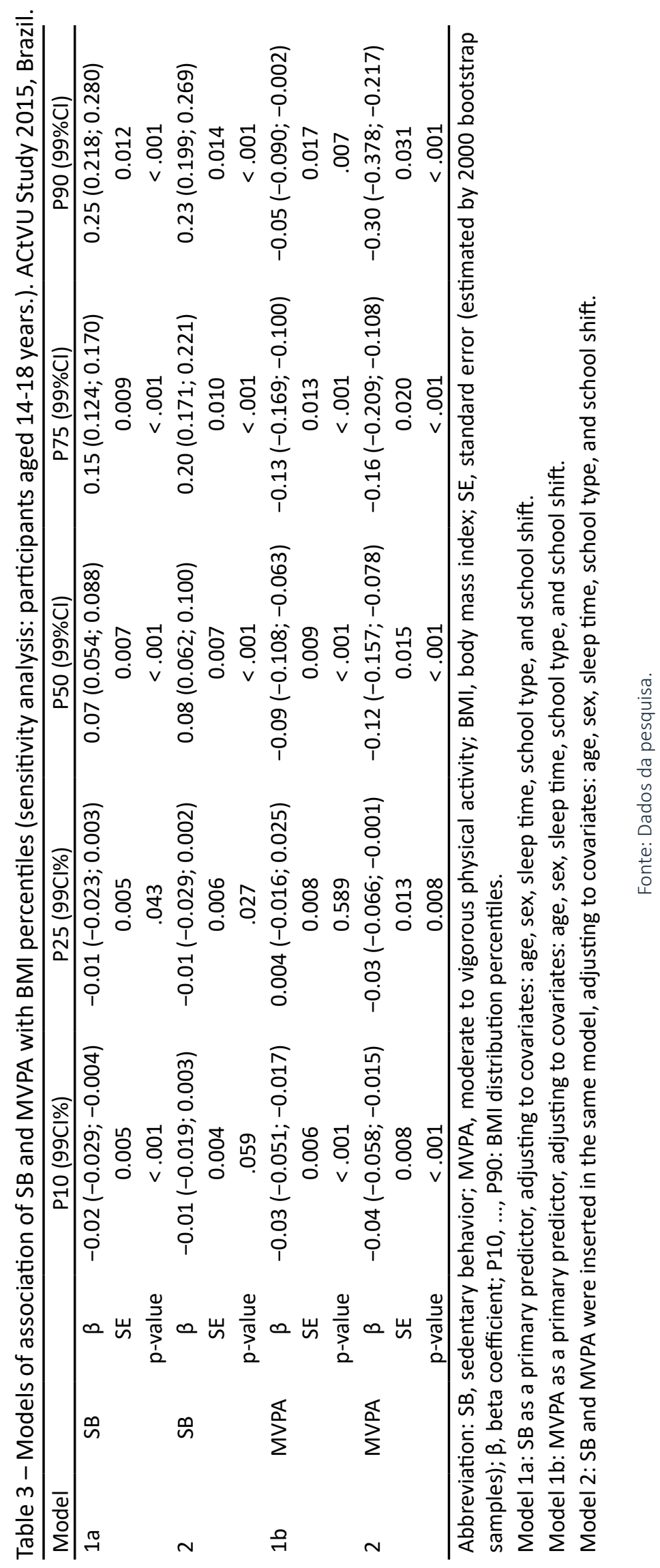


Figure 1 - Illustration of the quantiles regression associations between sedentary behavior (SB, left side), moderate to vigorous physical activity (MVPA, right side), and body mass index (BMI) percentiles. ACtVU Study 2015, Brazil.Discussion
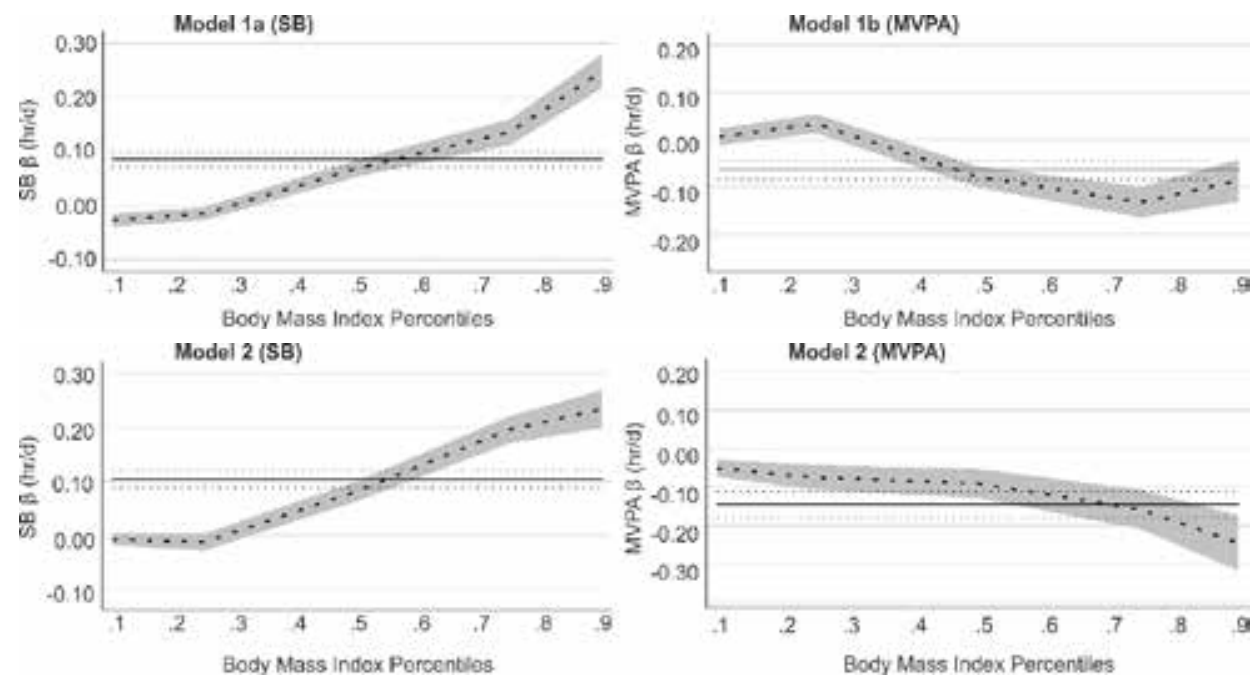

... BMI estimates at different regression percentiles

$1 \% 99 \mathrm{Cl}$ of the $\mathrm{BMI}$ estimates (quantile regression:"

- OLS BMI estimates (with same covariates)

$\% 99 \mathrm{CI}$ OLS (with the same covariates)

The results of the quantile regression of model 1a (SB as a primary predictor) and model $1 \mathrm{~b}$ (MVPA as a primary predictor) are shown in the top two figures; The two figures below show the results from model 2 . In model 2, SB and MVPA are included together. All constructed models (model $1 \mathrm{a}$, model $1 \mathrm{~b}$, and model 2) were adjusted for age, sex, and sleep time, type of school, and study shift. OLS - ordinary linear regression.

Fonte: Dados da pesquisa.

We used a representative sample of young Brazilian high school students and quantile regression analysis - an innovative approach among Brazilian surveys - to test whether SB and MVPA were independently associated with different percentiles of BMI distribution in young people. Our results revealed that a longer time spent on SB was independently associated with higher BMI values. In the same vein, the results showed that a longer time spent on MVPA was independently associated with lower BMI values. Still, the associations between $S B, M V P A$, and BMI were nonlinear; that is, the influence of exposures (SB and MVPA) was more significant at the higher percentiles of the distribution of the outcome variable (BMI).

Although causal relationships cannot be established by our cross-sectional study or the possibility of a two-way relationship between the investigated variables cannot be ruled out, the nonlinear relationship of our results allows us to infer that reducing/limiting SB and increasing MVPA may help to prevent and/or to alleviate obesity. The results we found for the associations between exposures (MVPA and SB) in the adjusted models support this assumption. For example, after adjusting for SB, higher MVPA values were associated with even lower $\mathrm{BMI}$ values in all percentiles, with the highest $\mathrm{BMI}$ distribution percentile (P90) being the one with the highest associative force. A previous study involving a sample of children and adolescents ( 6 to 18 years old) from six countries - not including Brazilians - showed that grater time watching television was independently associated with higher percentiles of BMI distribution. ${ }^{7}$ Other sedentary 


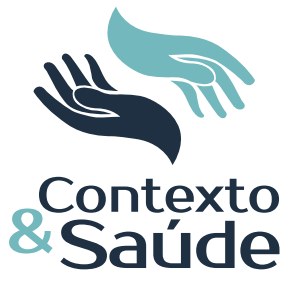

Editora Unijuí - Revista Contexto \& Saúde - ISSN 2176-7114 - v. 21, n. 44, out./dez. 2021 of MVPA we identified between screen-based SB and BMI percentiles. screen-based activities, in addition to watching television, may also be on the path to obesity among young people. ${ }^{18,19}$ Chaput and colleagues, ${ }^{18}$ for example, showed that a simple video game session increases intrasession energy expenditure [mean increase over resting: 89 kilojoules $(\mathrm{kJ})$ ], but the ad libtum caloric intake after the game exceeded that measured by rest ( $335 \mathrm{~kJ})$ - the increase in food consumption related to video games occurred even without an increased feeling of hunger. For this reason, we used the time spent on other screen sedentary activities in our sample of young people.

Obesity has been considered a global epidemic associated with several non-communicable diseases such as hypertension, diabetes, and certain types of cancer. For example, Casagrande, Waib and Sgarbi ${ }^{13}$ reported a $60 \%$ increase in abdominal obesity over fifteen years (2000-2015) in a cross-sectional study evolving Brazilian 12-18 years-old schoolchildren. In this scenario, SB ${ }^{20}$ and low levels of $\mathrm{MVPA}^{7}$ play a pivotal role in adiposity and consequently in chronic systemic inflammation.

Several studies have shown that SB measured by screen time is a risk factor for unfavorable body composition among young people, regardless of MVPA. ${ }^{5}$ Our study showed that this relationship of independence exists and also showed that the association between screen-based SB and BMI is nonlinear among Brazilian young people. Nevertheless, there is evidence that the total time in SB (measured by accelerometry) is not independently associated with BMI percentiles. ${ }^{7}$ However, screen time is one of the most common sedentary behaviors during free time among young people, especially with the advent of new media technologies that further increase the opportunities for young people to remain seated. ${ }^{21}$ The relationship between screen time and unfavorable body composition among young people is partially explained by the paradigm of posture/energy expenditure of the SB. ${ }^{22}$ This is because screen-based sedentary recreational activities also increase food consumption ${ }^{18}$ even in the absence of greater sensation of hunger, ${ }^{19}$ and also expose young people to advertisements - an influent factor favoring the adoption of unhealthy food patterns. ${ }^{23,24}$ This is, therefore, the ideal scenario for body energy imbalance: reduced expenditure and increased intake of calories. Taken together, both parts of the SB paradigm can help explain the independent associations

The potentialities of our study include the representative sample of young Brazilian high school students, which allows generalization to the survey population. In addition, this representative sample allowed us to perform adjusted analyses for important confounding variables as the research involves schoolchildren in Brazil. For example, the analyses were adjusted for the type of school, an important covariate because it has an intrinsic relationship with the variables of interest of the present study, especially BMI. ${ }^{14}$ We adopted the use of quantile regression which has certain advantages over linear regression. This regression method allows modeling data to the median (i.e., the 0.5 percentile) and any other percentile of the distribution of the outcome variable, without resorting to its categorization. ${ }^{6}$ Moreover, this regression method is more robust to statistical outliers, ${ }^{6}$ which is common in variables such as BMI. By using this statistical methodology, we were able to show the strong and independent associations 


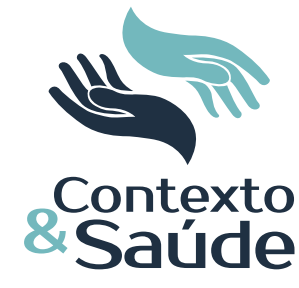

Editora Unijuí - Revista Contexto \& Saúde - ISSN 2176-7114 - v. 21, n. 44, out./dez. 2021 try). We have no assessed nutritional intake and pubertal status for adjusting our models, which may contribute to affect the results here showed. So, we recommend that further studies consider include it in approach in this research area.

Preventing obesity early in life may be the main strategy for reducing future health problems such as dyslipidemia, hypertension, and diabetes. Although complex, the etiological burden of SB and insufficient physical activity is recognized for pediatric obesity. ${ }^{4}$ Our results show that young people with the highest $\mathrm{BMI}$ values would benefit the most if they increased MVPA and reduced SB. Nevertheless, there is evidence that overweight young people are less susceptible to weight loss when the intervention only involves the reduction of screen-based $\mathrm{SB},{ }^{27}$ which is an additional challenge for intervention study developers. To be successful, in addition to focusing on structural changes in the environment, intervention designs should also consider the burden of the psychological factor linked to obesity in young people $e^{28}$ and include it as one of its components. It should also consider family involvement and the use of electronic devices to monitor sedentary time ${ }^{20}$ to be successful. In addition, the replacement of one SB with one MVPA may not occur completely, ${ }^{29}$ i.e. one SB (e.g. time in front of the screen) may be replaced by another (e.g. listening to music or reading/studying sitting), or by light physical activity (e.g. walking). Therefore, light physical activities should be valued for additional gains.

\section{CONCLUSION}

Screen-based SB and MVPA were independently associated with BMI in our representative sample of Brazilian youth. The quantile regressions revealed that the associations were nonlinear and more expressive in the upper percen-

between SB, MVPA, and the highest percentiles of BMI distribution. This would not have happened if we had adopted only linear regression as the main analysis of this study (see the $\beta$ coefficients in the results for comparison). The main limitation of our study is the use of self-reported measures of sedentary screen-based activities to estimate SB and MVPA. Despite our efforts to ensure that the measure reflected as best as possible the reality of daily lives of the young people (e.g., we separated behaviors by type of SB, by the time of the week [weekdays and weekend days], explained about the time sitting in front of a television, video game and/or computer-considering the time spent awake during the day), it is possible that the answers to the questions may have been over - or underestimated. Thus, we suggest that future studies test the replicability of our findings, overcoming this limitation (by using accelerometry in conjunction with self-report) and expanding the sample to nationally representative samples. Although we have used objective measures of height and body weight (rather than self-reported measures), BMI could be limited to represent the nutritional status of young people. However, this measure showed an acceptable ability to predict the total fat mass (TFM) in a sample of children and adolescents, ${ }^{25}$ and seems to be better applicable to predict TFM in older adolescents. ${ }^{26}$ Despite this, future studies should consider using other measures of body composition (e.g. skinfold thickness, bio-electrical impedance analysis, or dual-energy x-ray absorptiome- 
tiles of the BMI distribution. Our findings add information to previous results, suggesting that nonlinearity between exposures and outcomes should be considered when proposing future strategies for obesity prevention in youth.

\section{FUNDING}

This study was financed in part by the Coordenação de Aperfeiçoamento de Pessoal de Nível Superior- Brasil (Capes) - Finance Code 001

\section{DISCLOSURE}

We declare no conflicts of interest.

\section{ACKNOWLEDGMENTS}

To the Secretariat of Education of the State of Minas Gerais and the Regional Superintendence of Education of Uberaba. To the managers, teachers, and adolescents of the participating schools. To the members of the collection team.

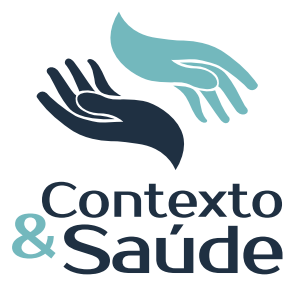

\section{REFERENCES}

${ }^{1}$ Rivera JÁ, de Cossío TG, Pedraza LS, Aburto TC, Sánchez TG, Martorell R. Childhood and adolescent overweight and obesity in Latin America: a systematic review. Lancet Diabetes Endocrinol. 2014;2(4):321-32.

${ }^{2}$ Silva KS da, Bandeira A da S, Santos PC dos, Malheiros LEA, Sousa ACFC de, Filho VCB. Systematic review of childhood and adolescence sedentary behavior: analysis of the Report Card Brazil 2018. Braz J Kinanthropometry Hum Perform. 2018;20(4):41545. Disponível em: https://periodicos.ufsc.br/index.php/rbcdh/article/view/ 1980-0037.2018v20n4p415

${ }^{3}$ Guthold R, Stevens GA, Riley LM, Bull FC. Global trends in insufficient physical activity among adolescents: a pooled analysis of 298 population-based surveys with 1.6 million participants. Lancet Child Adolesc Health. 2019;0(0). Disponível em: https://www.thelancet.com/journals/lanchi/article/PIIS2352-4642(19)30323-2/abstract

${ }^{4}$ Kumar S, Kelly AS. Review of Childhood Obesity: From Epidemiology, Etiology, and Comorbidities to Clinical Assessment and Treatment. Mayo Clin Proc. 2017 92(2):25165. Disponível em: https://www.mayoclinicproceedings.org/article/S0025-6196(16)30595-X/fulltext

${ }^{5}$ Biddle SJH, García Bengoechea E, Wiesner G. Sedentary behaviour and adiposity in youth: a systematic review of reviews and analysis of causality. Int J Behav Nutr Phys Act. 2017;14. Disponível em: https://www.ncbi.nlm.nih.gov/pmc/articles/PMC5371200/

${ }^{6}$ Beyerlein A. Quantile Regression - Opportunities and Challenges From a User's Perspective. Am J Epidemiol. 2014;180(3):330-1. Disponível em: https://academic.oup. com/aje/article/180/3/330/2739270

7 Mitchell JA, Dowda M, Pate RR, Kordas K, Froberg K, Sardinha LB, et al. Physical Activity and Pediatric Obesity: A Quantile Regression Analysis. Med Sci Sports Exerc.;49(3):466-73. Disponível em: https://www.ncbi.nlm.nih.gov/pmc/articles/ PMC5321492/

8 von Elm E, Altman DG, Egger M, Pocock SJ, Gøtzsche PC, Vandenbroucke JP. The Strengthening the Reporting of Observational Studies in Epidemiology (STROBE) Statement: Guidelines for Reporting Observational Studies. PLoS Med. 2007;4(10):1623-7. Disponível em: http://www.ncbi.nlm.nih.gov/pmc/articles/PMC2020495/ 


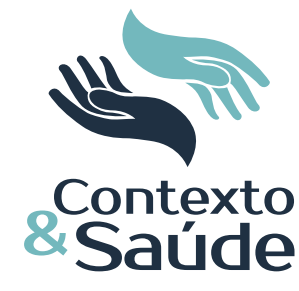

Editora Unijuí - Revista Contexto \& Saúde - ISSN 2176-7114 - v. 21, n. 44, out./dez. 2021 www.ncbi.nlm.nih.gov/pmc/articles/PMC4437561/ 2047-6310.2012.00064.x who.int/iris/handle/10665/37003 9. Disponível em: http://www.nature.com/pr/journal/v61/n6/full/pr2007158a.html Nutr. 2011;93(6):1196-203. Saúde. 2019;24:1-8. Disponível em: http://rbafs.org.br/RBAFS/article/view/13977 h2012-024 publications.org/content/early/2011/06/23/peds.2011-1066 http://linkinghub.elsevier.com/retrieve/pii/S0899900713002657 Pediatr. 1998;132(2):7.
${ }^{9}$ WHO. Youth and health risks - Report by the Secretariat. World Health Organization; 2011 [citado 28 jul. 2020]. Disponível em: https://apps.who.int/gb/ebwha/pdf_files/ WHA64/A64_25-en.pdf

${ }^{10}$ Silva KS da, Lopes A da S, Hoefelmann LP, Cabral LG de A, De Bem MFL, Barros MVG de, et al. Health risk behaviors Project (COMPAC) in youth of the Santa Catarina State, Brazil: ethics and methodological aspects. Braz J Kinanthropometry Hum Perform. 2013;15(1):1-15. Disponível em: http://www.scielo.br/scielo.php?script=sci_arttext\&pid=S1980-00372013000100001\&lng=en\&nrm=iso\&tlng=en

${ }^{11}$ Mitchell JA, Pate RR, Dowda M, Mattocks C, Riddoch C, Ness AR, et al. A prospective study of sedentary behavior in a large cohort of youth. Med Sci Sports Exerc. 2012;44(6):1081-7.

${ }^{12}$ Azevedo MR, Menezes AM, Assunção MC, Gonçalves H, Arumi I, Horta BL, et al. Tracking of physical activity during adolescence: the 1993 Pelotas Birth Cohort, Brazil. Rev Saúde Pública. 2014;48(6):925-30. Disponível em: http://www.scielo.br/scielo.php?script=sci_arttext\&pid=S0034-89102014000600925\&lng=en\&tlng=en

${ }^{13}$ Casagrande D, Waib PH, Sgarbi JA. Increase in the prevalence of abdominal obesity in Brazilian school children (2000-2015). Int J Pediatr Adolesc Med. 2017 Dec;4(4):133-7. Disponível em: http://www.sciencedirect.com/science/article/pii/S2352646717301023

${ }^{14}$ Leal DB, Assis MAA de, Conde WL, Lobo AS, Bellisle F, Andrade DF de. Individual characteristics and public or private schools predict the body mass index of Brazilian children: a multilevel analysis. Cad Saúde Pública. 2018;34:e00053117. Disponível em: https:// www.scielosp.org/article/csp/2018.v34n5/e00053117/en/

${ }^{15}$ Hale L, Guan S. Screen Time and Sleep among School-Aged Children and Adolescents: A Systematic Literature Review. Sleep Med Rev. 2015;21:50-8. Disponível em: https://

${ }^{16}$ Cole TJ, Lobstein T. Extended international (IOTF) body mass index cut-offs for thinness, overweight and obesity: Extended international BMI cut-offs. Pediatr Obes. 2012 Aug [citado 7 jan. 2016];7(4):284-94. Disponível em: http://doi.wiley.com/10.1111/j.

${ }^{17}$ WHO. Physical status: the use of and interpretation of anthropometry, report of a WHO expert committee. Geneva World Health Organ. 1995. Disponível em: http://www.

${ }^{18}$ Bellissimo N, Pencharz PB, Thomas SG, Anderson GH. Effect of television viewing at mealtime on food intake after a glucose preload in boys. Pediatr Res. 2007;61(6):745-

${ }^{19}$ Chaput J-P, Visby T, Nyby S, Klingenberg L, Gregersen NT, Tremblay A, et al. Video game playing increases food intake in adolescents: a randomized crossover study. Am J Clin

${ }^{20}$ Lourenço CLM, Souza TF de, Mendes EL. Relationship between smartphone use and sedentary behavior: a school-based study with adolescents. Rev Bras Atividade Física

21 Sedentary Behaviour Research Network. Letter to the editor: standardized use of the terms "sedentary" and "sedentary behaviours." Appl Physiol Nutr Metab. 2012;37(3):540-2. Disponível em: http://www.nrcresearchpress.com/doi/abs/10.1139/

${ }^{22}$ American Academy of Pediatrics. Policy Statement - Children, Adolescents, Obesity, and the Media. Pediatrics. 2011;128(1):201-8. Disponível em: http://pediatrics.aap-

${ }^{23}$ Ramos E, Costa A, Araújo J, Severo M, Lopes C. Effect of television viewing on food and nutrient intake among adolescents. Nutrition. 2013;29(11-12):1362-7. Disponível em:

${ }^{24}$ Pietrobelli A, Faith MS, Allison DB, Gallagher D, Chiumello G, Heymsfield SB. Body mass index as a measure of adiposity among children and adolescents: A validation study. J 
${ }^{25}$ Vanderwall C, Randall Clark R, Eickhoff J, Carrel AL. BMI is a poor predictor of adiposity in young overweight and obese children. BMC Pediatr. 2017;17. Disponível em: https:// www.ncbi.nlm.nih.gov/pmc/articles/PMC5457636/

${ }^{26}$ Maddison R, Marsh S, Foley L, Epstein LH, Olds T, Dewes O, et al. Screen-Time Weightloss Intervention Targeting Children at Home (SWITCH): a randomized controlled trial. Int J Behav Nutr Phys Act. 2014;11(1):111. Disponível em: https://doi.org/10.1186/ s12966-014-0111-2

${ }^{27}$ Barnett TA, Kelly AS, Young DR, Perry CK, Pratt CA, Edwards NM, et al. Sedentary Behaviors in Today's Youth: Approaches to the Prevention and Management of Childhood Obesity: A Scientific Statement from the American Heart Association. Circulation. 2018;138(11). Disponível em: https://www.ahajournals.org/doi/10.1161/ CIR.0000000000000591

${ }^{28}$ Conklin Al, Guo SXR, Yao CA, Tam ACT, Richardson CG. Stressful life events, gender and obesity: A prospective, population-based study of adolescents in British Columbia. Int J Pediatr Adolesc Med. 2019;6(2):41-6. Disponível em: http://www.sciencedirect.com/ science/article/pii/S2352646718302515

${ }^{29}$ Epstein LH, Roemmich JN. Reducing Sedentary Behavior: Role in Modifying Physical Activity: Exerc Sport Sci Rev. 2001;29(3):103-8. Disponível em: https://insights.ovid.com/ crossref?an=00003677-200107000-00003 